\title{
Dampak Riil Penghindaran Pajak Pada Perusahaan Manufaktur di Bursa Efek Indonesia
}

\author{
Dewi Kusuma Wardani \\ Safira Widya Putriane \\ Emi Puspitaningsih \\ Ambar Yuli Astuti \\ Nur Mutorikoh \\ Universitas Sarjanawiyata Tamansiswa \\ Jl. Kusumanegara 121 Yogyakarta \\ * d3wikusuma@gmail.com
}

\begin{abstract}
This study aims to examine the effect of tax avoidance to firm value, cost of capital, cash holding, capital structure. This sample used is a manufacturing companies during the year 2013-2017, based on the method of purposive sampling obtained 43 manufacturing companies. The stastical method used in this study was simple regression. This research results indicate that tax avoidance does not effect on the firm value, cash holding, and capital cost. Tax avoidance have a negative effect on the capital structure.
\end{abstract}

Keywords: Firm Value, Cost of Capital, Cash holding, Capital Structure, Tax Avoidance.

\section{PENDAHULUAN}

Pajak merupakan merupakan tumpuan terbesar dari belanja APBN Indonesia. Industri manufaktur merupakan penyumbang pajak tebesar bagi Negara. Bagi perusahaan manufaktur, pajak merupakan beban bagi perusahaan sehingga banyak perusahaan manufaktur yang melakukan upaya penghindaran pajak. Diduga setiap tahun penghindaran pajak sebesar Rp. 110 triliun atau 80\% dilakukan oleh wajib pajak badan usaha sisanya perorangan (www.suara.com). Hal ini terbukti pada tahun 2012 terdapat 4000 perusahaan PMA yang melaporkan pajaknya nihil dikarenakan mengalami rugi selama tujuh tahun berturut-turut. Pada umumnya perusahaan tersebut adalah perusahaan manufaktur dan pengolahan bahan baku (Astuti dan Aryani, 2016 dikutip dari Direktorat Jendral Pajak, 2013). Pada tahun 2014 DJP menyatakan PT. Toyota Motor Manufacturing melakukan penghindaran pajak sebesar Rp. 1,2 triliun atas impor mobil Toyota (www.tempo.com).
Kegiatan penghindaran pajak akan menimbulkan dampak baik maupun dampak buruk bagi perusahaan. Dampak pertama yang ditimbulkan adalah jatuhnya nilai perusahaan. Nilai perusahaan merupakan perspektif investor terhadap kinerja perusahaan di masa sekarang dan di masa yang akan datang. Praktik penghindaran pajak dapat menurunkan nilai perusahaan, karena dengan adanya praktik penghindaran pajak secara tidak langsung perusahaan akan menyajikan kondisi perusahaan yang tidak sebenarnya. Jika penghindaran pajak dilakukan dalam jangka waktu yang panjang dan terungkap ke publik maka, investor akan merasa dirugikan dan beranggapan bahwa perusahaan tidak kooperatif dalam menyajikan informasi yang dibutuhkan oleh investor sehingga investor hilang kepercayaan dan nilai perusahaan akan jatuh. Hal ini sejalan dengan penelitian yang dilakukan Santa dan Rezende (2016).

Dampak kedua adalah meningkatnya biaya modal. Penghindaran pajak akan menimbulkan adanya risiko pajak dimasa depan. Salah satu contoh 
risiko pajak di masa depan ialah pengenaan sanksi pajak. Jika suatu perusahaan di ketahui melakukan penyelewengan atas pajaknya, seperti tidak melaporkan sebagian penjualan atau memperbesar biaya dengan cara fiktif, maka perusahaan perusahaan tersebut mendapatkan sanksi atas pajaknya. Tentunya hal tersebut akan mempengaruhi kepercayaan investor dan kreditor terhadap perusahaan dan akan menyebabkan peningkatan biaya modal perusahaan yang tersirat. Dengan demikian, penghindaran pajak berpengaruh terhadap positif biaya modal. Hal ini sejalan dengan hasil penelitian Hutchens dan Rego (2013).

Dampak yang ketiga adalah penghindaran pajak akan meningkatkan cash holding. Perusahaan yang melakukan penghindaran pajak menghadapi risiko tertangkapnya oleh fiskus dan dimintai perusahaan harus membayar kekurangan pembayaran pajak beserta sanksi yang sangat besar. Untuk membayarnya maka perusahaan yang melakukan penghindaran pajak cenderung untuk meningkatkan cash holding. Penelitian ini sejalan dengan penelitian yang dilakukan Hanlon et al (2017)

Dampak yang keempat adalah turunnya struktur modal. Kreditur yang mengetahui bahwa perusahaan tersebut telah melakukan penghindaran pajak dan mengakibatkan adanya risiko ketidakpastian pajak membuat khawatir karena adanya kemungkinan perusahaan tersebut gagal bayar terhadap hutang yang diambil akibat harus melunasi denda dan kekurangan pajak yang belum terbayarkan Shevlin et al (2013). Oleh sebab itu kreditur cenderung meningkatkan bunga pinjaman dengan tujuan untuk memberatkan perusahaan, sehingga perusahaan tidak akan melakukkan pinjaman terhadap kreditur tersebut. Dengan adanya hutang yang semakin turun maka struktur modal juga akan semakin turun karena operasi perusahaan dibiayai secara internal. Hal ini didukung oleh penelitian yang dilakukan oleh Shevlin et al (2013) dan Midiastuty dkk (2017). Penelitian ini dilakukan untuk menguji dampak riil yang ditimbulkan dari kegiaan penghindaran pajak pada perusahaan manufaktur di Bursa Efek Indonesia (BEI).

\section{LANDASAN TEORI DAN PENGEMBANGAN HIPOTESIS}

\section{Teori Agensi}

Rahmatia (2015) mengungkapkan bahwa hubungan keagenan terjadi ketika satu atau lebih individu, yang disebut investor atau principal menyewa individu atau organisasi lain yang disebut agen (managemen) untuk melakukan sejumlah jasa atau mendelegasikan kewenangan untuk mengambil keputusan kepada agen tersebut. Rahmatia (2015) mengungkapkan jika kedua belah pihak memiliki tujuan yang sama dapat diyakini bahwa agen akan bertindak sesuai dengan keinginan principal. Manajemen memiliki kepentingan untuk menguntungkan diri sendiri seperti bonus dengan menahan laba perusahaan. Sedangkan principal menginginkan laba untuk dibagikan kepada pemegang saham dalam bentuk deviden. Tindakan penghindaran pajak yang dilakukan oleh manajemen akan mengakibatkan nilai perusahaan menurun, biaya modal perusahaan semakin tinggi, cash holding semakin tinggi, dan struktur modal menjadi rendah.

\section{Pengaruh Penghindaran Pajak terhadap Nilai Perusahaan}

$\begin{array}{llr}\text { Karimah dan Taufiq } & \text { (2015) } \\ \text { mengungkapkan berbagai cara } & \text { dapat } \\ \text { dilakukan oleh perusahaan } & \text { untuk }\end{array}$ meningkatkan nilai perusahaan, salah satunya menimalkan pajak yang harus dibayar atau penghindaran pajak (tax avoidance). Adanya tindakan penghindaran pajak berarti bahwa, perusahaan tidak menyajikan kondisi perusahaan yang sebenarnya, jika tindakan tersebut terungkap ke publik maka akan menyebabkan hilangnya kepercayaan masyarakat dan banyak investor yang 
mungkin akan menarik kembali dananya sehingga nilai perusahaan akan jatuh. Penelitian ini sejalan dengan penelitian yang dilakukan oleh Ampriyanti dan Lely (2016) dan Karimah dan Taufiq (2015). Penelitian ini bertolak belakang dengan penelitian yang dilakukan Tarihoran (2016). Berdasarkan uraian diatas maka hipotesis penelitian adalah:

\section{H1: Penghindaran pajak berpengaruh negatif terhadap nilai perusahaan.}

\section{Pengaruh Penghindaran Pajak terhadap Biaya Modal}

Penghindaran pajak akan mengakibatkan risiko pajak yang lebih besar sehingga akan meningkatkan ketidakpastian mengenai arus kas setelah pajak yang berlaku di masa depan. Hal ini akan mempengaruhi kepercayaan investor terhadap perusahaan dan akan menyebabkan peningkatan biaya modal perusahaan yang tersirat Hutchens dan Rego (2013). Hasil penelitian yang telah dilakukan Hutchens dan Rego (2013) menemukan bahwa risiko pajak (tax risk) berpengaruh positif terhadap biaya modal (cost of capital). Berdasarkan uraian diatas maka hipotesis penelitian adalah:

H2: Penghindaran pajak berpengaruh positif terhadap biaya modal (cost of capital)

\section{Pengaruh Penghindaran Pajak terhadap Cash Holding}

Perusahaan melakukan

penghindaran pajak melalui daerah abuabu yang ada dalam peraturan pajak. Tujuan penghindaran pajak adalah mencari berbagai celah yang dapat ditempuh dalam koridor peraturan perpajakan (loopholes), agar perusahaan dapat membayar pajak dalam jumlah minimal (Pohan, 2013). Penghindaran pajak akan menimbulkan ketidakpastian pajak di masa yang akan datang. Perusahaan yang melakukan penghindaran pajak akan menahan kas untuk tujuan pencegahan guna menghadapi tuntutan uang tambahan dari otoritas pajak atas penghematan pajak yang mereka lakukan (Hanlon et al, 2017). Tarif pajak efektif tunai yang relatif rendah, menghasilkan ketidakpastian pajak yang jauh lebih besar daripada perusahaan yang memiliki tarif pajak efektif tunai yang lebih tinggi (Dyreng. et al, 2017). Hal ini sejalan dengan penelitian yang dilakukan Hanlon (2017). Berdasarkan uraian penelitian tersebut maka hipotesis penelitian adalah :

\section{H3: Penghindaran pajak berpengaruh positif terhadap cash holding}

\section{Pengaruh Penghindaran Pajak terhadap Struktur Modal}

Penghindaran pajak yang dilakukan tidak sesuai dengan peraturan maka nantinya perusahaan akan dikenai sanksi berupa denda atau bunga atas pembayaran kurang pajak. Hal tersebut yang menjadi penyebab penghindaran pajak yang dilakukan oleh perusahaan mendatangkan ketidakpastian pajak di masa yang akan datang (Shevlin et al., 2013). Ketika adanya risiko atau ketidakpastian pajak yang harus ditanggung di masa depan maka kreditor akan lebih wasapada dan hati-hati dalam memberikan pinjaman sehingga struktur modal menurun. Oleh sebab itu, semakin tinggi penghindaran pajak maka semakin rendah struktur modal perusahaan. Hal ini didukung oleh penelitian yang dilakukan oleh Shevlin et al (2013) dan Midiastuty dkk (2017). Berdasarkan uraian diatas maka hipotesis penelitian ini adalah:

\section{H4 : Penghindaran pajak berpengaruh negatif terhadap struktur modal.}

\section{METODE PENELITIAN}

Penelitian ini mengggunakan data sekunder. Populasi yang digunakan dalam penelitian ini adalah perusahaan manufaktur yang terdaftar di Bursa Efek Indonesia tahun 2013-2017. Pemilihan sampel dalam penelitian ini adalah metode purposive sampling. Uji asumsi klasik yang digunakan dalam penelitian ini terdiri dari uji autokorelasi dan uji heteroskesdastisitas. Uji multikolineritas 
tidak digunakan karena model analisis merupakan regresi sederhana. Uji normalitas dalam penelitian ini tidak dilakukan, tetapi menggunakan asumsi normalitas. Penelitian Smith \& Wells (2006) menemukan bahwa dipilih 175 sampel untuk mendapatkan sampel yang berdistribusi normal, menjadi normal ketika melebihi 200 sampel. Uji multikolonieritas tidak digunakan dalam penelitian ini karena merupakan analisis regresi sederhana. Berdasarkan pertimbangan dalam pemilihan sampel yang telah disesuaikan dengan kriteria pengambilan sampel penelitian, maka diperoleh sampel sebagai berikut:

\section{Tabel 1}

Data Pemilihan Sampel

\begin{tabular}{llc}
\hline No & \multicolumn{1}{c}{ Kriteria } & Jumlah \\
\hline 1 & $\begin{array}{l}\text { Perusahaan manufaktur } \\
\text { yang terdaftar di Bursa } \\
\text { Efek Indonesia pada tahun } \\
2013-2017 .\end{array}$ & 143 \\
2 & $\begin{array}{l}\text { Perusahaan yang } \\
\text { menerbitkan laporan } \\
\text { keuangan dalam mata } \\
\text { uang asing }\end{array}$ \\
3 & $\begin{array}{l}\text { Perusahaan yang memiliki } \\
\text { laba negatif } \\
\text { Perusahaan yang tidak } \\
\text { memiliki data mendukung }\end{array}$ & \\
\hline & Jumlah sampel & $(59)$ \\
\hline
\end{tabular}

\section{Teknik Analisis}

Model analisis yang digunakan adalah analisis regresi linier sederhana yang dirumuskan sebagai berikut:

$$
\mathrm{Y}=\mathrm{C}+\mathrm{X}
$$

Keterangan:

$\mathrm{Y}=$ Nilai perusahaan, biaya modal, cash holding, struktur modal.

$\mathrm{C}=$ Konstanta.

$\mathrm{X}=$ Penghindaran pajak.

\section{HASIL PENELITIAN DAN PEMBAHASAN}

Penelitian ini menggunakan analisis regresi linear sederhana. Peneliti melakukan uji asumsi klasik terlebih dahulu sebelum melakukan uji analisis regresi linear sederhana. Berdasarkan hasil uji autokorelasi dan heteroskedastisitas data sudah terbebas dari masalah asumsi klasik.

\section{Statistik Deskriptif}

Tabel 2

Hasil Uji Statistik Deskriptif

\begin{tabular}{llllll}
\hline & Mean & Ma & Mi & $\begin{array}{l}\text { Std. } \\
\text { Deviasi }\end{array}$ & $\mathrm{N}$ \\
\hline CETR & 0,408 & 9,893 & 0,0075 & 0,7265 & 215 \\
NP & 1,572 & 55,900 & 0,0010 & 6,0293 & 215 \\
BM & 0,045 & 0,640 & 0,0001 & 0,0622 & 215 \\
CH & 0,120 & 0,702 & 0,0025 & 0,1215 & 215 \\
DER & 0,794 & 5,152 & 0,7089 & 0,7686 & 215 \\
\hline
\end{tabular}

Variabel nilai perusahaan memiliki rata-rata sebesar 1.572 , artinya rata-rata perusahaan manufaktur yang terdaftar di BEI memiliki nilai perusahaan sebesar $157,2 \%$. Deviasi standar dari nilai perusahaan manufaktur sebesar $602,9 \%$. Deviasi standar nilainya lebih besar dari rata-rata. Hal tersebut menunjukkan bahwa variabel penghindaran pajak memiliki varian sebaran yang besar dilihat dari ratarata sampel yang digunakan.

Variabel biaya modal memiliki rata-rata sebesar 0.045 , artinya rata-rata perusahaan manufaktur yang terdaftar di BEI memiliki biaya modal sebesar $4,5 \%$. Deviasi standar dari biaya hutang perusahaan manufaktur sebesar 0.0622 . Deviasi standar nilainya lebih kecil dari rata-rata. Hasil tersebut menunjukan bahwa data variabel biaya modal, sebaran atau variabilitasnya rendah, artinya data yang digunakan mengelompok diseputar nilai rata-ratanya. Sehingga pada setiap perusahaan nilai biaya modal besarannya hampir merata atau sama.

Variabel cash holding memiliki nilai rata-rata sebesar 0,120 , artinya ratarata perusahaan manufaktur yang terdaftar di BEI memiliki cash holding sebesar 12 $\%$. Deviasi standar dari cash holding perusahaan manufaktur adalah sebesar 
0,1215. Deviasi standar nilainya lebih besar dari rata-rata. Sehingga variabel penghindaran pajak memiliki varian sebaran yang besar dilihat dari rata-rata sampel yang digunanakan.

Variabel struktur modal memiliki nilai rata-rata sebesar 0,794 , artinya ratarata perusahaan manufaktur yang terdaftar di BEI memiliki cash holding sebesar $79,4 \%$. Deviasi standar dari struktur modal perusahaan manufaktur adalah sebesar 0,7686. Deviasi standar nilainya lebih besar dari rata-rata. Sehingga variabel penghindaran pajak memiliki varian sebaran yang besar dilihat dari rata-rata sampel yang digunakan.

Penghindaran pajak dengan proxy CETR memiliki nilai rata-rata sebesar 0,408 artinya rata-rata perusahaan manufaktur yang terdaftar di BEI memiliki tingkat penghindaran pajak sebesar $40,8 \%$ dari laba sebelum pajak. Deviasi standar sebesar 0,7265, nilainya lebih besar dari rata-rata. Sehingga variabel penghindaran pajak memiliki varian sebaran yang besar dilihat dari rata-rata sampel yang digunanakan.

\section{Pembahasan}

Pengaruh Penghindaran Pajak terhadap Nilai Perusahaan

\section{Tabel \\ Hasil Uji CETR terhadap Nilai Perusahaan}

\begin{tabular}{ccccc}
\hline Variabel & \multicolumn{2}{c}{ Unstandarized } & \multicolumn{1}{l}{ t- } & Prob \\
& $\mathrm{B}$ & Std. Eror & statistic & \\
\hline C & $-1,910$ & 0,471 & $-4,034$ & 0,0001 \\
LOG(CETR) & 0,108 & 0,136 & 0,793 & 0,4289 \\
AR(1) & 0,768 & 0,044 & 17,340 & 0,0000 \\
\hline
\end{tabular}

untuk $\begin{gathered}\text { Pengujian hipotesis ini dilakukan } \\ \text { membuktikan }\end{gathered}$ penghindaran pajak yang diproksikan dengan CETR terhadap nilai perusahaan. Berdasarkan tabel diatas CETR memiliki probabilitas sebesar $0,4289>0,05$ artinya penghindaran pajak dengan proksi CETR tidak berpengaruh terhadap nilai perusahaan. Hal ini membuktikan bahwa investor dalam melakukan investasi tidak memperhatikan seberapa besar penghindaran pajak yang dilakukan perusahaan. Investor lebih melihat bagaimana perusahaan menggunakan dananya untuk operasional perusahaan dan meningkatkan laba. Sehingga penghindaran pajak yang dilakukan perusahaan tidak berpengaruh terhadap nilai perusahaan. Penelitian ini sejalan dengan penelitian yang dilakukan Rahmatia (2015) dan Salawu et al (2017)

\section{Pengaruh Penghindaran Pajak terhadap Biaya Modal}

Tabel 3

\section{Hasil Uji CETR terhadap Biaya Modal}

\begin{tabular}{ccccc}
\hline Variabel & \multicolumn{2}{c}{ Unstandarized } & t- statistic & Prob \\
& B & Std. Eror & & \\
\hline C & $-3,7396$ & 0.2138 & -17.4898 & 0.0000 \\
LOG(CETR) & 0.0643 & 0.1035 & 0.6212 & 0.5351 \\
AR(1) & 0.5790 & 0.0564 & 10.2692 & 0,0000 \\
\hline
\end{tabular}

Pengujian hipotesis ini dilakukan untuk membuktikan pengaruh penghindaran pajak yang diproksikan dengan CETR terhadap biaya modal. Berdasarkan tabel di atas CETR memiliki probabilitas sebesar $0,5351>0,05$ artinya penghidaran pajak dengan proksi CETR tidak berpengaruh terhadap biaya modal. Hal ini terjadi karena biaya modal pada sampel penelitian ini relatif rendah sehingga dapat menurunkan resiko kegagalan membayar hutang perusahan yang dampaknya dapat mengurangi biaya hutang perusahaan, sehingga tidak terlalu memberi dampak besar terhadap penghindaran pajak (Pratama, dkk 2017). Berbeda dengan penelitian yang dilakukan oleh Hutchens dan Rego (2013) bahwa penghindaran pajak lebih besar akan meningkatkan ketidakpastian mengenai arus kas setelah pajak yang berlaku di masa depan, dan ini akan mempengaruhi kepercayaan investor terhadap perusahaan dan akan menyebabkan peningkatan biaya modal. Hasil penelitian ini sejalan dengan 
Pratama dkk (2017) dan tidak sejalan dengan penelitian Hutchens dan Rego (2013).

\section{Pengaruh Penghindaran Pajak terhadap Cash Holding}

Tabel 4

\begin{tabular}{cccll}
\hline Variabel & \multicolumn{2}{c}{ Unstandarized } & t- & Prob \\
& B & Std. Eror & statistic & \\
\hline C & -2.8815 & 0.2126 & -13.5507 & 0.0000 \\
LOG(CETR) & -0.1437 & 0.08305 & -1.73095 & 0.0849 \\
AR(1) & 0.6774 & 0.05103 & 13.2746 & 0,0000 \\
\hline
\end{tabular}

untuk $\begin{gathered}\text { Pengujian hipotesis ini dilakukan } \\ \text { membuktikan }\end{gathered}$ penghindaran pajak yang diproksikan dengan CETR terhadap cash holding. Berdasarkan tabel diatas CETR memiliki probabilitas sebesar 0,0849>0,05 artinya Penghindaran pajak dengan proksi CETR tidak berpengaruh terhadap cash holding. Hal ini membuktikan bahwa perusahaan di Indonesia akan sangat berhati-hati dalam memutuskan langkah penyelesaian pajaknya. Karena ketika perusahaan melakukan keberatan atas Surat Ketetapan Pajak (SKP) tetap harus membayar kewajiban perpajakannya minimal sejumlah yang disetujuinya. Perusahaan akan berpikir ulang ketika akan melakukan keberatan atau banding atas kewajiban perpajakannya. Hal ini membuat penghindaran pajak tidak memiliki pengaruh terhadap cash holding Hardianto dkk (2017). Berbeda dengan penelitian yang dilakukan Hanlon et al (2017) perusahaan di Amerika Serikat cenderung menumpuk kas untuk berjaga-jaga atas penghindaran pajak yg dilakukan karena adanya peraturan FIN 48 tentang pengungkapan Contingent Tax Benefit. Sedangkan di Indonesia tidak ada peraturan tersebut. Hasil penelitian ini sejalan dengan penlitian Hardianto dkk (2017) dan tidak sejalan dengan penelitian Hanlon et al (2017).

\section{Pengaruh Penghindaran Pajak terhadap Struktur Modal}

Tabel 5

Hasil Uji CETR terhadap Struktur Modal

\begin{tabular}{ccccc}
\hline Variabel & \multicolumn{2}{c}{ Unstandarized } & t- statistic & Prob \\
& $\mathrm{B}$ & Std. Eror & & \\
\hline C & -0.4004 & 0.1734 & -2.3097 & 0.0219 \\
LOG(CETR) & 0.1433 & 0.0469 & 3.0536 & 0.0026 \\
AR(1) & 0.7829 & 0.0429 & 18.2188 & 0,0000 \\
\hline
\end{tabular}

Pengujian hipotesis ini dilakukan
untuk membuktikan penghindaran pajak yang diproksikan dengan CETR terhadap struktur modal. Berdasarkan tabel diatas CETR memiliki probabilitas sebesar $0,0026<0,05$ artinya Penghindaran pajak dengan proksi CETR berpengaruh negatif terhadap struktur modal. Ketidakpastian pajak berpengaruh negatif terhadap struktur modal artinya semakin tinggi ketidakpastian pajak yang dialami perusahaan karena penghindaran pajak akan mengakibatkan struktur modal suatu perusahaan menjadi semakin rendah. Hal ini dikarenakan ketika perusahaan melakukan penghindaran pajak atau memanfaatkan loopholes, celah yang dimanfaatkan adalah celah yang bersifat grey area, pada saat perusahan memanfaatkan celah tersebut maka perusahaan akan terpapar risiko akan dikenai sanksi atau denda di masa yang akan datang. Dengan demikian ketika adanya kemungkinan pembayaran sanksi pajak dimasa yang akan datang maka arus kas perusahaan di masa yang akan datang juga menjadi tidak pasti, perusahaan terpapar akan risiko pembayaran dimasa depan. Semakin tinggi tingkat risiko perusahaan harus membayar sanksi, maka kreditur akan semakin khawatir untuk meminjamkan modal atau menginvestasikan dananya kepada perusahaan Shevlin et al (2013). Hal tersebut akan mengakibatkan struktur modal perusahaan berkurang. Hal ini sejalan dengan penelitian yang dilakukan oleh Shevlin et al (2013). Penelitian ini 
bertolak belakang dengan pennelitian yang dilkukan Midiastuty dkk (2017).

\section{PENUTUP}

Hasil penelitian ini mengungkapkan bahwa penghindaran pajak tidak berpengaruh terhadap nilai perusahaan, cash holding, dan biaya modal. Hasil penelitian ini mengungkapkan bahwa penghindaran pajak berpengaruh negatif terhadap struktur modal.

\section{Implikasi}

Berdasarkan hasil penelitian yang telah dilakukan maka dapat kita ketahui bahwa penghindaran pajak memiliki pengaruh negatif terhadap struktur modal. Variabel penghindaran pajak tidak memiliki pengaruh terhadap nilai perusahaan, biaya modal, dan cash holding. Maka implikasi dari penelitian ini adalah perusahaan yang melakukan penghindaran pajak tinggi aka memiliki struktur modal yang rendah. Penghindaran pajak yang dilakukan dengan memanfaatkan gray area maka perusahaan akan semakin berisiko untuk mebayar sanksi pajak dimasa depan. Dengan melakukan penghindaran pajak para kreditur akan menjadi khawatir terhadap kemampuan perusahaan dapat mengembalikan dana pinjaman yang telah diberikan. Ketika para kreditur ragu maka para kreditur akan menaikan bunga pinjaman agar memberatkan perusahaan, dan perusahaan mengurungkan niatnya untuk meminjam dana dari perusahaan tersebut. Oleh karena itu lebih baik perusahaan tidak melakukan penghindaran pajak agar tidak akan dikenai sanksi yang dapat menurunkan struktur modal perusahaan dan akan meminimalkan risiko kebangkrutan.

\section{Keterbatasan}

Penelitian ini masih memiliki beberapa keterbatasan sebagai berikut:

a. Dalam menjelaskan dampak riil penghindaran pajak penelitian ini memfokuskan pada empat dampak riil yaitu nilai perusahaan, biaya modal, cash holding, dan struktur modal

b. Penelitian ini hanya menggunakan perusahaan manufaktur sebagai sampel sehingga hasil penelitian ini tidak dapat digeneralisasikan pada jenis perusahaan lain seperti property dan real estate, telekomunikasi, perbankan, tambang, infrastruktur dan crude palm oil.

\section{Saran}

Berdasarkan hasil penelitian ini dan pembahasan sebelumnya dapat ditarik beberapa saran sebagai berikut:

a. Penelitian selanjutnya bisa menguji dampak apa saja yang dapat ditimbulkan dari kegiatan penghindaran pajak diluar variabel yang telah diteliti dalam penelitian ini.

b. Penelitian selanjutnya bisa menggunakan sampel perusahaan lain untuk membuktikan dampak dari kegiatan penghindaran pajak diluar perusahaan manufaktur.

\section{Daftar Pustaka}

Ampriyanti, N. M., \& Lely, M. A. N. K. (2016). Pengaruh Tax Avoidance Jangka Panjang Terhadap Nilai Perusahaan dengan Karakter Eksekutif Sebagai Variabel Moderasi. E-Journal Akuntansi Universitas Udayana, 16, 2231-3359.

Dyreng, S., Hanlon, M., \& Maydew, E. L. (2017). When Does Tax Avoidance Result in Tax Uncertainty? Ssrn, (C), 2005-2008. https://doi.org/10.2139/ssrn.2374945

Hanlon, M., Maydew, E. L., \& Saavedra, D. (2017). The taxman cometh: Does tax uncertainty affect corporate cash holdings? Review of Accounting Studies, 22(3), 1198-1228. https://doi.org/10.1007/s11142-0179398-y

Hardianto, T. Y., Kustiani, A. N., \& Ramadhan, R. M. (2017). Pengaruh Tax Avoidance Risk Terhadap Cash Holding Policy Perusahaan di 
Indonesia. Jurnal Soedirman Accounting Review, 02.

Hutchens, M., \& Rego, S. (2013). Tax Risk and The Cost of Equity Capital. Journal, Indiana University.

Karimah, H. N. K., \& Taufiq, E. (2015). Pengaruh Tax Avoidance Terhadap Nilai Perusahaan. Jurnal Fakultas Ekonomi UPN Veteran Jakarta.

Midiastuty, P. P., Eddy, S., \& Kristiana. (2017). Pengaruh Penghindaran Pajak Terhadap Struktur Modal Perusahaan, 37-61.

https://doi.org/https://dx.doi.org/10.11 11/febs. 12555

Pohan, A. C. (2013). Manajemen Perpajakan Strategi Perencanaan Pajak dan Bisnis. Jakarta: PT Gramedia Pustaka Utama.

Pratama, N., Djaddang, S., \& Masri, I. (2017). Pengujian Tax Avoidance dan Risiko Kebangkrutan Terhadap Cost of Debit dan Insentif Pajak Sebagai Pemoderasi. Konferensi Ilmiah Akuntansi IV.

Rahmatia, T. L. (2015). Pengaruh Kepemilikan Manajerial terhadap Nilai Perusahaan: Tanggung Jawab Sosial sebagai Variabel Moderating. Jurnal Ilmu \& Riset Akuntansi, 4.

Salawu, R. O., Ogundipe, L. O., \& Yeye, O. (2017). Granger Causality between Corporate Tax Planning and Firm Value of Non- Financial Quoted Companies in Nigeria Department of Management and Accounting Department of Business Education Finance and Accounts Department. International Journal of Business and Social Science, 8(9), 91-103.

Santa, S. L. L., \& Rezende, A. J. (2016). Elisão fiscal e valor da firma: evidências do Brasil. Revista Contemporânea de Contabilidade, 13(30), 114-133. https://doi.org/http://dx.doi.org/10.50 07/2175-8069.2016v13n30p114

Shevlin, T., Urcan, O., \& Florin, V. (2013). Corporate Tax Avoidance and Public Debt Cost, 1-59.
Smith, Z. R., \& Wells, C. S. (2006). Central Limit Theorem and Sample Size. The annual meeting of the Northeastern Educational Research Association, 1-22.

Tarihoran, A. (2016). Pengaruh Penghindaran Pajak dan Leverage Terhadap Nilai Perusahaan dengan Transparansi Perusahaan Sebagai Variabel Moderasi. Jurnal Wira Ekonomi Mikroskil, 6, 149-164.

www.suara.com. (n.d.). Setiap Tahun Penghindaran Pajak Capai Rp. 110 Triliun. Diambil 11 November 2018, dari https://www.suara.com/

Www.tempo.com. (n.d.). Prahara Pajak Raja Otomotif. Diambil 11 November 2018, dari https://www.tempo.com/ 